\title{
PROJETO FEIRÃO DO JOÃO: INTEGRANDO ESCOLA E COMUNIDADE
}

\section{JOÃO FEIRÃO PROJECT: INTEGRATING SCHOOL AND COMMUNITY}

\author{
Tailur Mousquer Martins (tailurmartins@bol.com.br) \\ Escola Estadual de Ensino Médio João Przyczynski \\ Professor Preceptor Bolsista CAPES Projeto Residência Pedagógica
}

\begin{abstract}
Resumo: A alta produção e geração de resíduos sólidos urbanos têm se tornado um agente causador de grande quantidade de poluição no meio ambiente. Tendo isso em vista, desenvolveu-se o projeto intitulado Feirão do João, que teve por objetivo conscientizar os alunos sobre como a reciclagem e reutilização de materiais que seriam descartados como lixo poderiam ter ainda valor agregado, além de aliar a isto o conhecimento prático de conceitos estudados em sala de aula. Durante a realização do projeto, foram recolhidos materiais na comunidade que posteriormente foram vendidos pelos alunos em uma feira na escola. $\mathrm{O}$ valor arrecadado com as vendas foi revertido aos alunos e aplicado em viagens de estudo. O projeto obteve grande sucesso na comunidade e proporcionou o desenvolvimento de senso crítico nos alunos, além da conscientização sobre a importância da preservação e conservação do meio ambiente, bem como o valor que aquilo que é tido como lixo por alguns, pode ter valor para outros.
\end{abstract}

Palavras-chave: projeto social; descarte de resíduos; reaproveitamento de materiais.

\begin{abstract}
The high production and generation of municipal solid waste has become an agent that causes a large amount of pollution in the environment. With this in mind, the project called Feirão do João was developed, which aimed to make students aware of how the recycling and reuse of materials that would be discarded as garbage could still have added value, as well as combining the practical knowledge of concepts studied in the classroom. During the project, community materials were collected and later sold by students at a school fair. The amount collected from sales was reverted to students and applied on study trips. The project was very successful in the community and provided students with critical thinking, awareness of the importance of preserving the environment, and the value that what may be trashed by some may have value to others.
\end{abstract}

Recebido em: 27/08/2019

Aceito em: 10/10/2019 


\section{Vol. 2, n. 3 - Edição Especial: Ciclos Formativos em Ensino de Ciências.}

Keywords: social Project; waste disposal; reuse of materials.

\section{INTRODUÇÃO}

$\mathrm{O}$ atual período histórico é marcado pelo consumismo exacerbado e, devido a este, tem-se um excesso de produção e descarte de materiais que poderiam ser reciclados ou reutilizados. Há ainda, uma elevada produção de materiais que são descartados de maneira errônea ou irregular tanto em lixeiras domésticas quanto públicas ou em locais inadequados como terrenos baldios e afluentes, o que leva a poluição destes locais e exerce forte influência em futuros problemas relacionados à saúde e ao meio ambiente.

Neste contexto, buscou-se criar um projeto que possibilitasse desenvolver um senso crítico nos alunos e na comunidade sobre os resíduos e rejeitos produzidos em casa, na escola e na sociedade como um todo; uma alterativa que pudesse ser colocada em prática, de modo a despertar nestas pessoas a ideia de serem protagonistas sociais, tendo como referenciais teóricos os conceitos abordados nas aulas de Biologia.

Tendo em vista ainda a necessidade de levar os alunos em locais diferentes daquele da sala de aula para buscar uma melhor compreensão de conceitos através de viagens e passeios didáticos, e considerando as dificuldades para conseguir fechar ônibus com os alunos das diferentes turmas do ensino médio principalmente devido à falta de recursos dos mesmos, desenvolveu-se um projeto que permitiu unir tanto a conservação e reaproveitamento de materiais como a obtenção de recursos financeiros, através dessas ações, a fim de investir na melhoria da educação dos próprios alunos. Considerando-se todos estes fatores, surgiu à ideia do projeto social entre a escola e a comunidade denominado "Feirão do João", em homenagem ao nome da própria escola, que desde o ano de 2014 vem sendo desenvolvido na Escola Estadual de Ensino Médio João Przyczynski, localizada no centro urbano de Guarani das Missões, no Estado do Rio Grande do Sul. O projeto intitulado Feirão do João, tem como objetivo conscientizar sobre a geração de resíduos sólidos seja pela produção ou pelo consumo, ou ainda pela inanição destes materiais nas residências ou centros comerciais. 


\section{Vol. 2, n. 3 - Edição Especial: Ciclos Formativos em Ensino de Ciências.}

Ao se tratar da questão da produção e do descarte dos resíduos sólidos e orgânicos gerados, principalmente, nas residências dos alunos e da comunidade escolar, deparou-se com o problema de como fazer com que os alunos aprendessem a importância e relevância da conscientização sobre o excesso de materiais que armazenamos e descartamos todos os dias e, ainda, quanto do que se coloca fora poderia ser reaproveitado pelo próprio sujeito ou por outro que precisasse de tais materiais.

Roupas, calçados, sacolas, bolsas, entre outros itens, são, normalmente, objetos que podem ser doados para campanhas de agasalho ou entidades que façam a distribuição para aqueles que mais necessitam. Porém, utensílios de cozinha, sobras de construção, pneus, sobras de oficina mecânica, eletrodomésticos estragados ou inutilizados, bijuterias, móveis, livros e revistas, entre tantos outros objetos, são, muitas vezes, descartados diretamente na lixeira sendo, ou não, reaproveitados nos centros municipais de coleta. Entretanto, o que se encontra, em muitos centros urbanos, assim como em comunidades rurais, são depósitos a céu aberto contendo estes materiais, que poderiam ser reutilizados ou transformados em outros objetos com valor agregado.

Algo que nos motivou a criar o projeto foi o trabalho realizado pelo artista plástico e fotógrafo brasileiro Vik Muniz (1961 - ) no Jardim Gramacho (RJ), registrado no documentário Lixo Extraordinário (2010), onde foi feito um trabalho de conscientização sobre os materiais que são descartados no aterro e que poderiam ser reaproveitados (Santos, 2011). No caso do projeto de Vik, estes materiais foram convertidos em arte, conscientizando as pessoas que vivem e sobrevivem do "lixo" sobre o valor daquilo que a sociedade descarta e menospreza, pois "Vik fotografa o catador/personagem, constrói uma imagem que inclui significantes recolhidos do testemunho de vida, transformando-o em modelo da própria obra" (DIOGO, 2011,p.02).

\section{DESCRIÇÃO DAS ATIVIDADES}

Durante as aulas da disciplina de Biologia, apresentou-se aos alunos o documentário Lixo Extraordinário, de 2010, dirigido por Lucy Walker, que trata do trabalho do artista plástico e fotógrafo brasileiro Vik Muniz junto aos catadores de 


\section{Vol. 2, n. 3 - Edição Especial: Ciclos Formativos em Ensino de Ciências.}

materiais recicláveis do aterro de Jardim Gramacho, em Duque de Caxias, no Rio de Janeiro. No decorrer da película, o espectador vai conhecendo os motivos que levam o artista a sair da sua zona de conforto e se submeter, por aproximadamente dois anos, a realizar algumas fotomontagens usando os materiais do aterro, mas, além disso, ou em consequência disso, a mudar a vida daquelas pessoas que foram escolhidas para participar do projeto.

Estes catadores tornam-se protagonistas de sua própria história que se mescla ao trabalho de Muniz. Em meio a dramas e emoções, o espectador vai sentido carisma por cada um daqueles sujeitos, destacando-se: Tião Santos, o presidente da associação dos catadores de Jardim Gramacho; Valter, vice-presidente da associação, sempre lembrado pela frase: “99 não são 100” (Lixo Extraordinário, 2010) ao falar sobre a importância de diminuir o que se consume ou se coloca no lixo; além de Ísis, Magna, Zumbi, Suelym e Irma. Cada um deles conquista e sensibiliza quem se dispõe a conhecê-los. Assim foi na sala de aula e na escola.

Ao término do documentário fez-se uma reflexão escrita individual por cada um dos alunos, na qual estes descreveram o que sentiram sobre o documentário e como analisavam seu entendimento sobre o tema do lixo e produção de resíduos. Além disso, muitos mostraram-se dispostos a mudar o comportamento sobre como descartavam e o que descartariam na lixeira. Entretanto, Maria Clara Tomaz Machado e Priscylla Leite de Moraes, no artigo Lixo extraordinário: a arte de criar, reciclar e representar, nos alertam que "O vídeo documentário, assim como os textos, pode ser classificado como verossimilhante, mas não manifesta a total e completa verdade dos fatos [...]"(MACHADO; DE MORAES, 2014, p. 03).

Tendo essas ideias e consciência da necessidade da urgência de mudar e conscientizar não apenas os alunos, mas as famílias e comunidade sobre o problema do consumismo e da geração de resíduos, propôs-se a criação e desenvolvimento de um projeto que ligasse a escola e a comunidade, levando os conhecimentos adquiridos para além dos muros da escola.

Assim, os alunos do ensino médio foram organizados em grupos que, a partir de um cronograma de saídas em horários intercalados, pudessem sair pelas ruas da 


\section{Vol. 2, n. 3 - Edição Especial: Ciclos Formativos em Ensino de Ciências.}

cidade, batendo de casa em casa ou em pontos comerciais, pedindo doações daquilo que poderia estar sobrado naqueles locais e que seriam colocados logo, ou no futuro, no lixo, mas que se fossem doados poderiam ter utilidade para outras pessoas. A ideia foi recolher tudo aquilo que poderia estar sobrando ou se acumulando em armários, despensas, sótãos, garagens, pátios, entre outros locais, e que seria mais cedo ou mais tarde colocado no lixo, seja pelo não uso ou por estragar pela ação do tempo. Tudo aquilo a ser coletado seria posteriormente vendido numa feira dentro da escola, mas com valores modestos e acessíveis, sendo aberta a toda comunidade.

Para a divulgação inicial foi devolvido um slogan e uma frase de efeito: "Abra seu coração e participe do Feirão do João", a fim de sensibilizar a comunidade para o tema proposto. Ainda, desenvolveram-se faixas e cartazes que foram expostos na escola.

Com isso, foram coletados diferentes materiais num intervalo de quase dois meses do início do projeto, sendo que o primeiro foi realizado em maio de 2014. Dentre os materiais coletados, pode-se destacar: roupas, calçados, sacolas e mochilas, cintos, carteiras, sofás, eletrodomésticos (televisores, rádios, secadores, aparelhos de vídeo, lavadoras,...), armários, brinquedos, louças, talheres, livros, discos, fitas de vídeo e cassete, panelas, pratos, bijuterias, perfumes, telhas, tabuas, pneus, bicicletas, entre muitos outros. Foram os mais variados e diversificados, extrapolando todas as expectativas.

Após essa coleta, realizou-se o processo de organização, limpeza e seleção do que estava em bom estado e daquilo que precisava ser consertado ou customizado, para que pudesse ser assim comercializado na culminância do projeto, que ocorreria num sábado durante o dia todo.

Durante o dia das vendas os alunos tiveram outra oportunidade: a de interagir com o público oferecendo os produtos. Muitos, nesse processo, foram perdendo a timidez de falar em público e, posteriormente, em sala de aula tornaram-se mais atuantes no desenvolvimento de atividades em grupo ou trabalhos em equipe.

As vendas, então, superaram as expectativas ultrapassando a marca de $\mathrm{R} \$$ 5000,00 , que foram totalmente revertidos para os alunos. Desde o início, a proposta era que o montante do lucro das vendas, excluídas então as despesas para faixas, banners e 


\section{Vol. 2, n. 3 - Edição Especial: Ciclos Formativos em Ensino de Ciências.}

panfletos, seria revertida para os alunos das turmas atuantes e participantes, a fim de fazer uso em algo que melhorasse o ensino-aprendizagem da turma, tal como livros, assinatura de revistas, viagens ou excursões. A decisão do uso do recurso obtido era de responsabilidade da turma junto ao seu professor conselheiro-regente.

Os conteúdos contemplados no projeto se iniciam naqueles da área das Ciências, principalmente da Biologia, tais como: ciclos da matéria (biogeoquímicos), conservação dos solos e mananciais, conservação de ecossistemas e, ainda, movimentação ambientalista. Entretanto, o projeto amplia-se indo de encontro com conteúdos de outras áreas do conhecimento, tais como: Linguagens - na produção e confecção de cartazes, propaganda e confecção artística através do reaproveitamento de materiais quebrados; Matemática - na questão econômica, contabilidade e finanças e; na área de Humanas com interação social, conhecimentos e reconhecimentos de ruas e bairros, e formação da cidadania.

\section{DISCUSSÃO}

Após o diagnóstico realizado com os alunos a partir do documentário Lixo extraordinário, e as reflexões acerca do tema lixo, resíduos e poluição, foram organizados grupos de trabalho com os alunos das três turmas do ensino médio, a saber $1^{\circ}$ a $3^{\circ} \mathrm{s}$ anos, que assim sairiam nas ruas e bairros, divulgado e explicando os objetivos do trabalho: receber doações daquilo que está sobrando, obsoleto ou que iria ser colocado fora, mas que ainda poderia ser utilizado, ou útil, a outras pessoas, e com isso diminuir a quantidade de materiais a serem levados para os aterros ou depósitos clandestinos de lixo e entulhos.

Foi organizado ainda nesse período, o material para divulgação: panfletos, faixa na frente da escola e banner. Para a confecção desse material utilizou-se a criatividade dos próprios alunos na elaboração do slogan e uma marca (desenho). Esse material serviu de base para melhorar a comunicação entre escola e comunidade, e também criar uma identidade para o projeto. 


\section{Vol. 2, n. 3 - Edição Especial: Ciclos Formativos em Ensino de Ciências.}

Os alunos ao saírem às ruas foram aprendendo, aos poucos, a melhorar a comunicação e expressão. Alguns que, inicialmente, eram mais tímidos foram se destacando e sendo, às vezes, os principais protagonistas nas conversas com o público.

Após essa fase de divulgação, em um intervalo de quinze dias, aproximadamente, os alunos voltaram a percorrer o mesmo caminho a fim de recolher as possíveis doações. Quando houve maior volume ou quantidade de materiais, auxiliou-se aqueles que precisavam, fazendo o transporte dos materiais até a escola em veículo próprio do professor.

Feita a coleta, começou-se a fase de separação, limpeza e catalogação. A triagem é importante para uma melhor organização para o dia do evento, onde ocorreriam as vendas. Os valores dados as doações para móveis ou eletrodomésticos em bom estado variou entre 20 e 30 reais, contudo, a maioria dos itens foi revendida a valores menores que 5 reais, para que fosse bastante acessível a comunidade.

Durante o período de coleta até a venda, foram feitas divulgações em rádios locais, tendo presença dos alunos nestes veículos. Também ocorreu divulgação por meio das redes sociais, o que facilitou a divulgação e, também, as doações recebidas.

Em todo esse percurso, a maioria dos alunos se dispôs a trabalhar e atuar de maneira a colaborar não só com a escola mas também com a comunidade, porém havia sempre, em cada turma, dois ou três, que infelizmente não se dispunham a colaborar mesmo tendo um caráter social e ao final os lucros pela venda das doações serem revertidas para os próprios alunos.

Vale ressaltar que o projeto sempre teve como objetivo o aluno, isto é, o valor obtido com a venda dos produtos seria dos alunos e, nunca da direção ou professores, mas deveriam eles, os alunos, buscar usar em algo relacionado a aprendizagem, tal como viagem, excursão ou saída em algum evento. Isso, talvez, seja o fundamental nesse projeto a aprendizagem de que a partir daquilo que seria colocado fora, que seria lixo, se conseguiria obter recurso para uma viagem ou outra coisa que, antes disso, os alunos não teriam condições de ir.

A feira ocorreu sempre no sábado, sendo a escola organizada um dia antes. Todos os objetos recolhidos foram limpos e consertados, organizados em pequenos 


\section{Vol. 2, n. 3 - Edição Especial: Ciclos Formativos em Ensino de Ciências.}

setores, tais como roupas masculinas, femininas e infantil, calçados, bolsas e cintos, eletrodomésticos, bazar, brinquedos, móveis, oficina, informática, entre outros, não chegamos a contabilizar a quantidade de itens, mas as fotos em anexo mostram que foi uma grande quantidade.

O horário, da feira, sempre foi das $9 \mathrm{~h}$ às $16 \mathrm{~h}$. Durante esse intervalo muitas pessoas visitaram a escola vindas de diferentes locais do município. Em questão de meia hora, arrecadou-se mais de mil reais, sendo impressionante observar a quantidade de pessoas na fila do caixa e com tantas coisas escolhidas em tão pouco tempo após a abertura.

Os alunos estavam organizados em turnos de duas horas de trabalho durante esse dia, cada uma aprendendo a lidar com o público agora de uma maneira diferente: teriam que saber vender seus produtos, saber comercializar. Numa cidade de pequeno porte, isso se torna fundamental pois, muitos destes alunos, um dia iniciarão suas vidas no mercado lojista e assim tiveram a oportunidade de aprender a calcular e tratar com paciência e cordialidade todas aquelas pessoas.

\section{CONCLUSÃO}

$\mathrm{O}$ trabalho, a princípio, precisou romper as barreiras impostas pela descrença e pessimismo sobre a dificuldade de colocar em prática, e sobre a colaboração da comunidade nas doações e posteriormente na venda dos objetos arrecadados. Porém, o pós-venda ajudou a consolidar e confirmar o projeto.

Assim, após o sucesso de primeiro Feirão, e com a realização das edições posteriores, sendo este um relato da quarta edição, o projeto vem contando cada vez mais com uma maior participação e interesse por parte de toda a comunidade.

O projeto criou uma identidade para a escola, inexistente até então, tanto com os alunos quanto com a comunidade. A criação e o desenvolvimento do Feirão do João proporcionam não apenas uma maior interação com os conceitos pré-estabelecidos nas ementas da disciplina de Biologia, mas também uma interligação de saberes junto às outras áreas do conhecimento, isto é, as outras ciências. 


\section{Vol. 2, n. 3 - Edição Especial: Ciclos Formativos em Ensino de Ciências.}

Tratar dos temas, conceitos e disciplinas escolares fora do ambiente fechado da sala de aula motiva e cativa os educandos para a aprendizagem, criando vínculos que podem perdurar o tempo de escola e formar cidadãos com maior responsabilidade ao assumir seus direitos e deveres tanto enquanto alunos como no período após a conclusão dos estudos no Ensino Médio.

Com isso, a avaliação é feita pela participação e comprometimento em protagonizar o projeto. Ao término de cada edição, procurou-se, através do diálogo em sala de aula, saber quais foram os pontos positivos e negativos, pela visão do aluno, do projeto e, com isso, tentar melhorar e corrigir, não apenas este, mas todo e qualquer outro projeto de sala de aula ou extraclasse que venha a ser desenvolvido.

Depois do interesse e participação, de toda comunidade escolar e municipal, não mais se questiona se tal projeto pode ser feito, mas ao contrário, quando será feito. A escola ganhou com o projeto, uma identidade, e os alunos, uma aprendizagem de vida e convivência social, aprendendo na prática a fazer coleta, separação, venda e, algo muito significativo: conhecer e atuar na comunidade como um agente de transformação social. Assim, após o sucesso de primeiro Feirão foram realizados anualmente outras edições, sendo a quinta edição realizada em 2018 que contou com uma maior participação tanto da escola quanto da comunidade.

\section{REFERÊNCIAS}

DIOGO, Doris R. Vik Muniz e os artifícios de socialização na atualidade. Latusa Digital Ano 8, n.46, Set. de 2011.

LIXO EXTRAORDINÁRIO. Direção: Lucy Walker. Produção: Hank Levine e Angus Aynsley. Intérprete: Vik Muniz. [S.1]: Paris Filmes, 2010. 1DVD (99 min), son., color.

MACHADO, Maria C. T.; DE MORAES, Priscylla L. Lixo extraordinário: a arte de criar, reciclar e representar. Cad. Pesq. Cdhis, Uberlândia, v.27, n.1, jan./jun., 2014.

SANTOS, Darlan; FUX, Jacques. Estamira e Lixo Extraordinário: a arte na terra desolada. IPOTESI, Juiz de Fora, v.15, n.2, 125-137, jul./dez. 2011. 